\title{
APLIKASI FUZZY LOGIC DALAM DIAGNOSA PENYAKIT DIABETES MELLITUS PADA PUSKESMAS DI JAKARTA TIMUR
}

\author{
Za'imatun Niswati1,*, Aulia Paramita ${ }^{1}$, Fanisya Alva Mustika ${ }^{1}$ \\ 1Teknik Informatika, Universitas Indraprasta PGRI \\ (cooresponding author) zaimatunnis@gmail.com *)
}

\begin{abstract}
Patients with diabetes mellitus increased from year to year. This is due to delays in diagnosis of the disease and also because of unhealthy lifestyles. This study aims to create an application of decision support systems in the field of health, namely the diagnosis of the disease Diabetes Mellitus with Fuzzy Inference System (FIS) Mamdani, so that a layman can perform early diagnosis and immediate treatment. Decision Support System Techniques developed to improve the effectiveness of decision-makers. Samples are six puskesmas in East Jakarta. This application uses five variables as inputs consisting of glucose 2 hours after a meal, Diastolic blood pressure, body mass index, family history of diabetes, total pregnancies and one variable as output. The data obtained be processed using fuzzy logic approach to programming Matlab and made Graphical User Interface (GUI). Result is an expert system for diagnosis of Diabetes Mellitus .The trial results by midwives and nurses puskesmas is $100 \%$ of these applications in accordance with the doctor"s diagnosis. It is to help improve the quality of service in the Puskesmas in East Jakarta, thus satisfying the users and puskesmas be able to compete both nationally and internationally.
\end{abstract}

Keywords: Fuzzy Inference System (FS) Mamdani, Matlab, Graphical User Interface (GUI), Diabetes Mellitus.

Intisari- Penderita Diabetes Mellitusmeningkat dari tahun ke tahun. Hal ini dikarenakan keterlambatan diagnosa penyakit dan juga karena gaya hidup yang tidak sehat. Penelitian ini bertujuan membuat sebuah aplikasi dari sistem pendukung keputusan dalam bidang kesehatan yaitu diagnosa penyakit Diabetes Mellitusdengan metode Fuzzy Inference System (FIS) Mamdani, sehingga orang awam dapat melakukan diagnosa secara dini dan dapat segera melakukan pengobatan. Teknik Sistem Pendukung Keputusan dikembangkan untuk meningkatkan efektivitas dari pengambil keputusan. Sampel pada penelitian ini adalah 6 Puskesmas yang ada di Jakarta Timur. Aplikasi ini menggunakan lima variabel sebagai input yang terdiri dari kadar glukosa 2 jam setelah makan, tekanan darah diastolic, indeks massa tubuh, riwayat diabetes dalam keluarga, banyaknya kehamilan dan satu variabel sebagai output. Data yang diperoleh diolah menggunakan pendekatan logika fuzzy dengan pemrograman Matlab dan dibuat Graphical User Interface (GUI). Hasil dari penelitian ini adalah suatu sistem pakar untuk diagnosa penyakit Diabetes Mellitus. Hasil ujicoba oleh bidan dan perawat puskesmas adalah $100 \%$ aplikasi ini sesuai dengan diagnosa dokter.Aplikasi ini dapat membantu meningkatkan mutu pelayanan di Puskesmas Jakarta Timur, sehingga memuaskan pengguna dan puskesmas dapat bersaing baik ditingkat nasional maupun internasional.

Kata Kunci: Fuzzy Inference System (FIS) Mamdani, Matlab, Graphical User Interface (GUI), Diabetes Mellitus.

\section{PENDAHULUAN}

Metode kecerdasan buatan (Artificial Intelligence /AI) sangat banyak digunakan dalam segala bidang termasuk aplikasi di bidang kesehatan/kedokteran. Teknologi softcomputing adalah sebuah bidang kajian penelitian interdisipliner dalam ilmu komputasi dan kecerdasan buatan. Beberapa teknik dalam softcomputing antara lain sistem pakar (expert system), jaringan syaraf tiruan (neural networks), logika fuzzy (fuzzy logic), dan algoritma genetik (genetic algorithms) banyak dikembangkan karena mempunyai keunggulan dalam penyelesaian masalah yang mengandung ketidakpastian, ketidaktepatan dan kebenaran parsial, termasuk dalam bidang kesehatan [1].

Menurut Dr. Johanes Chandrawinata, MND, SpGK, tren resiko kesehatan bergeser dari resiko tradisional (malnutrisi, kebersihan sanitasi, dll) ke resiko modern (obesitas, diabetes, kolesterol, dll). Dr. Johanes, ahli nutrisi RS. Boromeus Bandung mengungkapkan, transisi perubahan gaya hidup ini membuat 10 penyakit menjadi pembunuh utama di Indonesia, terutama warga perkotaan, ungkapnya saat MoU Kalbe Farma dengan Tipco di Jakarta. la merinci, ke- 10 penyakit itu ialah: strok (19,4 persen), diabetes mellitus (9,3 persen), hipertensi (7,5 persen), TB (7,3 persen), jantung iskesmik (6,5 persen), tumor ganas (5,8 persen), penyakit hati/liver (5,5 persen), NEC (5,3 persen), penyakit jantung lain (5,1 persen), dan penyakit saluran nafas bawah kronik (4,7 persen), [2]. 
Diagnosa penyakit diabetes mellitus selama ini dilakukan oleh dokter spesialis dengan memperhatikan gejala fisik, keluhan pasien dan hasil tes laboratorium. Dengan adanya suatu aplikasi praktis yang dapat diterapkan secara efisien dan efektif untuk mendiagnosa penyakit diabetes mellitusmaka orang awam dapat melakukan diagnosa secara dini dan dapat segera melakukan pengobatan. Dengan aplikasi diabetes mellitus ini maka diagnosa yang dilakukan cukup objektif.

\section{TINJAUAN PUSTAKA}

Secara umum, sistem pakar merupakan sistem yang mengadopsi pengetahuan manusia ke dalam komputer sehingga komputer dapat digunakan untuk menyelesaikan suatu masalah sebagaimana yang dilakukan oleh seorang pakar. Sistem pakar dibuat pada wilayah pengetahuan tertentu dan untuk suatu keahlian tertentu yang mendekati kemampuan manusia di salah satu bidang khusus. Sistem pakar mencoba mencari solusi yang memuaskan sebagaimana yang dilakukan seorang pakar dan dapat memberikan penjelasan terhadap langkah yang diambil serta memberikan alasan atas kesimpulan yang diambil [3].

Pusat Kesehatan Masyarakat, disingkat Puskesmas, adalah Organisasi fungsional yang menyelenggarakan upaya kesehatan yang bersifat menyeluruh, terpadu, merata, dapat diterima dan terjangkau oleh masyarakat. Upaya kesehatan tersebut diselenggarakan dengan menitikberatkan kepada pelayanan untuk masyarakat luas guna mencapai derajat kesehatan yang optimal, tanpa mengabaikan mutu pelayanan kepada perorangan.

Diabetes Melitus dikelompokkan menjadi dua tipe yaitu DM tergantung insulin (DM tipe-1) dan DM tidak tergantung insulin (DM tipe-2). DM tipe 1 biasanya menimbulkan gejala sebelum usia pasien 30 tahun, walaupun gejala dapat muncul kapan saja. Pasien DM tipe1 memerlukan insulin dari luar tubuhnya untuk kelangsungan hidupnya. DM tipe 2 biasanya dialami saat pasien berusia 30 tahun atau lebih, dan pasien tidak tergantung dengan insulin dari luar tubuh, kecuali pada keadaan-keadaan tertentu. Sebagian besar kasus adalah DM tipe-2 yang banyak ditemukan pada orang yang mengalami obesitas atau kegemukan akibat pola hidup yang dijalaninya. Sementara, DM tipe-1 banyak dipengaruhi faktor keturunan, meski kontribusi faktor keturunan terhadap risiko DM hanya sebesar 5\%. Selain itu, terdapat DM yang dikenal dengan DM gestasional yang terjadi selama masa kehamilan, yang disebabkan oleh gangguan toleransi glukosa pada pasien tersebut [4].

\section{A. Fuzzy Inference System (FIS) Mamdani}

Sebelum munculnya teori logika fuzzy(fuzzy logic) dikenal sebuah logika tegas (crisp logic) yang memiliki nilai benar dan salah secara tegas. Sebaliknya Logika Fuzzy adalah suatu logika yang memiliki nilai kekaburan atau kesamaran (fuzzyness) antara benar dan salah. Dalam teori logika fuzzysuatu nilai bisa bernilai benar dan salah secara bersamaan. Namun berapa besar kebenaran dan kesalahan suatu nilai tergantung pada bobot keanggotaan yang dimilikinya. Orang yang belum mengenal logika fuzzy pasti akan mengira bahwa logika fuzzy adalah suatu yang amat rumit dan tidak menyenangkan. Namun, sekali orang mengenalnya, ia pasti akan sangat tertarik dan akan menjadi pendatang baru untuk ikut serta mempelajari logika fuzzy. Logika fuzzy dikatakan sebagai logika baru yang lama, sebab ilmu tentang logika fuzzy modern dan metodis baru ditemukan beberapa tahun yang lalu, padahal sebenarnya konsep tentang logika fuzzy itu sendiri sudah ada pada diri kita sejak lama [3].

Metode Mamdani sering juga dikenal dengan nama Metode Max-Min. Metode ini diperkenalkan oleh Ebrahim Mamdani pada tahun 1975.Untuk mendapatkan output, diperlukan 4 tahapan:

1). Pembentukan himpunan fuzzy. Pada proses fuzzifikasi langkah yang pertama adalah menentukan Variabel fuzzy dan himpunan fuzzynya. Kemudian tentukan derajat keanggotaan antara data masukan fuzzy dengan himpunan fuzzy yang telah didefenisikan untuk setiap variabel masukan sistem dari setiap aturan fuzzy. Pada metode mamdani, baik variabel input maupun variabel output dibagi menjadi satu atau lebih himpunan fuzzy.

2) . Aplikasi fungsi implikasi pada metode mamdani. Fungsi implikasi yang digunakan adalah min. Hasil implikasi fuzzy dari setiap aturan ini kemudian digabungkan untuk menghasilkan keluaran inferensi fuzzy.

3). Komposisi Aturan (rule). Tidak seperti penalaran monoton, apabila sistem terdiri dari beberapa aturan, maka inferensi diperoleh dari kumpulan dan korelasi antar aturan. Ada 3 metode yang digunakan dalam melakukan inferensi sistem fuzzy, yaitu: max, additive dan probabilistik OR.

4). Penegasan (defuzzy). Input dari proses defuzzifikasi adalah suatu himpunan fuzzy yang diperoleh dari komposisi aturan-aturan fuzzy, sedangkan output yang dihasilkan merupakan suatu bilangan pada domain himpunan fuzzy tersebut [5]. 


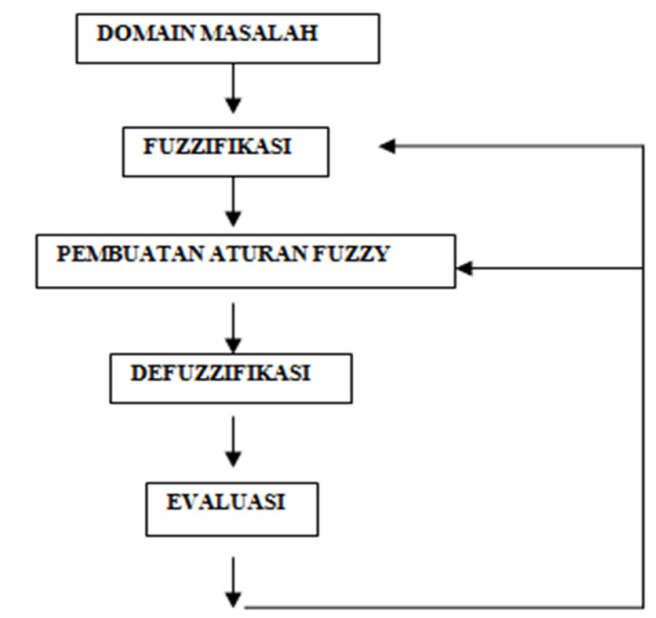

Gambar 1. Pengembangan Fuzzy Inference System Mamdani

B. Matlab Toolbox: Fuzzy

Agar dapat menggunakan fungsi-fungsi logika fuzzy yang ada pada Matlab, maka harus diinstall terlebih dahulu Toolbox Fuzzy. Fuzzy Logic toolbox (FLT) memberikan fasilitas Graphical User Interface (GUI) untuk mempermudah dalam membangun, mengedit, dan mengobservasi sistem penalaran fuzzy, yaitu:

1). Fuzzy Inference System (FIS) Editor

2). Membership Function Editor

3). Rule Editor

4). Rule Viewer

5). Surface Viewer [6].

\section{METODOLOGI PENELITIAN}

Penelitian yang dilaksanakan adalah jenis penelitian eksperimen yaitu membuat aplikasi Fuzzy Inference System (FIS) Mamdani dalam diagnosa penyakit diabetes mellitus berdasarkan hasil tes laboratorium. Populasi penelitian ini adalah seluruh puskesmas di Jakarta Timur dan sampel diambil secara random 6 puskesmas.

Alur penelitian system pakar Fuzzy Inference System (FIS) Mamdani dalam diagnosa penyakit diabetes mellitus akan mengikuti tahapan. Kegiatan penelitian ini melalui beberapa tahap dalam pengembangannya, yaitu :

1. Penelitian pendahuluan

Kegiatan yang dilakukan pada saat studi pendahuluan yaitu mengumpulkan materi-materi kepustakaan yang berhubungan dengan judul penelitian. Kemudian langkah selanjutnya yaitu pengambilan data sekunder di puskesmas. Dari data tersebut akan di dapat beberapa kriteria yang digunakan untuk penelitian lebih lanjut.

\begin{tabular}{clc} 
& \multicolumn{1}{c}{ Tabel 1. Variabel Himpunan Fuzzy } & \\
\hline \multirow{2}{*}{ Fungsi } & Nama Variabel & $\begin{array}{c}\text { Semesta } \\
\text { Pembicara } \\
\text { an } \\
\text { (Nilai/Rang } \\
\text { e) }\end{array}$ \\
\hline \multirow{2}{*}{ Input } & Glukosa plasma 2 jam & {$[0-10]$} \\
\cline { 2 - 3 } & Tekanandarah diastolik $(\mathrm{mm} \mathrm{Hg})$ & {$[0-10]$} \\
\cline { 2 - 3 } & Indeks massa tubuh & {$[0-10]$} \\
\cline { 2 - 3 } & Fungsisilsilah Diabetes & {$[0-10]$} \\
\cline { 2 - 3 } & Jumlah kali hamil & {$[0-10]$} \\
\hline Output & Skor Hasil tes Laboratorium & {$[0-10]$} \\
\hline
\end{tabular}


2. Data

Sampel data yang digunakan pada penelitian ini adalah data sekunder dari Puskesmas di Jakarta Timur dan database UCI Data Set yang disediakan oleh Center for Machine Learning and Intelligent Systemsat the University of California, Irvine. Objek penelitian adalah data pasien diabetes mellitus. Diambil sebanyak 200 pasien yang terdiri dari 100 pasien diabetes mellitus dan 100 pasien non diabetes mellitus yang dipilih secara acak dari populasisebanyak 200 pasien diabetes mellitus dan sebanyak 200 pasien non diabetes mellitus.

Dari 200 kasus tersebut 120 kasus (60\%) digunakan sebagai data training, 80 kasus (40\%) digunakan sebagai data testing. Data training untuk pembentukan aplikasi, dan data testing digunakan untuk pengujian aplikasi.

3. Pengolah data

Data yang diperoleh akan diolah menggunakan pendekatan Fuzzy Inference System (FIS) Mamdani dengan bantuan toolbox Matlab.

4. Metode Pengumpulan Data

Penelitian yang dilakukan untuk menghasilkan data dan informasi yang diperlukan serta berhubungan dengan hal yang akan ditulis. Untuk mengumpulkan data serta informasi yang diperlukan oleh peneliti menggunakan metode pengumpulan data primer dan sekunder dari Puskesmas di Jakarta Timur.

5. Instrument Penelitian

a. Penelitian ini menggunakan data primer dan data sekunder berupa data penyakit Diabetes mellitus yang digunakan sebagai instrumentasi guna memperoleh data dalam proses diagnosa penyakit.

b. Data disajikan dalam bentuk Tabulasi model dan variabel masing- masing sebanyak 100 pasien diabetes mellitus dan sebanyak 100 pasien non diabetes mellitus.

c. Perangkat lunak yang digunakan untuk menganalisis adalah Fuzzy Inference System (FIS) Mamdani menggunakan Toolbox Matlab dan Graphical User Interface (GUI).

6. Teknik Analisis Data

Analisis data menggunakan kuantitatif dengan kaidah-kaidah matematika terhadap data angka atau numerik. Pembentukan himpunan fuzzy pada variabel input maupun variabel output dibagi menjadi satu atau lebih himpunan fuzzy. Aplikasi fungsi implikasi yang digunakan untuk tiap-tiap aturan adalah fungsi min. Penegasan (defuzzy) menggunakan bantuan software matlab dengan menggunakan fasilitas yang disediakan pada toolbox fuzzy.

7. Langkah-langkah Penelitian

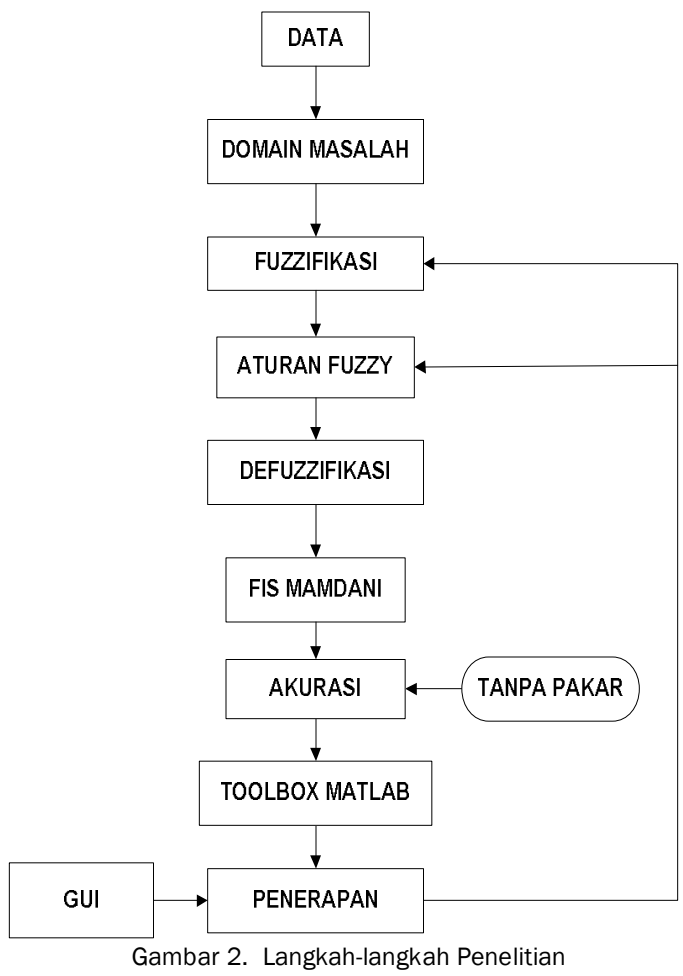


Langkah-langkah penelitian merupakan pengembangan Fuzzy Inference System (FIS) Mamdani terdiri dari :

1. Domain masalah

a. Kelayakan suatu permasalahan tidak diselesaikan atau sulit apabila dengan nilai crisp

b. Oleh karena itu, diusulkan suatu pendekatan penyelesaian masalah berbasis fuzzy

c. Pada tahap ini ditentukan pula variabel-variabel fuzzy yang akan digunakan dalam sistem

2. Fuzzifikasi

a. Tahap ini adalah tahap untuk mengubah nilai crisp dari suatu parameter menjadi variable linguistic

b. Pada tahap ini semua variabel fuzzy harus dibuat menjadi himpunan fuzzy

c. Umumnya menggunakan beberapa kurva sebagai representasi fuzzy dari suatu variabel. Misalnya : Kurva Triangular, Kurva Trapezoidal, Kurva Gausian.

3. Pembuatan Aturan Fuzzy

a. Aturan fuzzy dibuat untuk memetakan setiap input terhadap output yang akan dicapai

b. Dikenal dengan if-then fuzzy

c. Pembuatan aturan sebaiknya dilakukan bersama pakar

4. Defuzzifikasi

a. Defuzifikasi dilakukan untuk mendapatkan kembali nilai crisp dari sejumlah aturan yang telah dibuat

b. Akan bergantung dari metode Reasoning yang digunakan : Mamdani

5. Evaluasi

a. Evaluasi dilakukan untuk menguji output dari aplikasi yang dihasilkan

b. Evaluasi bisa dilakukan dengan dua cara :

1. Dilakukan bersama pakar: dengan memberikan kombinasi input kepada pakar untuk kemudian pakar diminta menilai hasilnya dan dicocokkan dengan sistem

8. Pengujian

2. Dilakukan tanpa pakar : apabila terdapat data uji [7]

Pengujian aplikasi diagnosa penyakit Diabetes Mellitusdilakukan bersama bidan dan perawat pada pasien prolanis di puskesmas untuk menguji output dari aplikasi yang dihasilkan.

\section{HASIL DAN PEMBAHASAN}

A. Pengelompokan Data

Untuk pemilihan sampel pasien Diabetes Mellitus (DM), data sekunder dari database UCl Data Set yang disediakan oleh Center for Machine Learning and Intelligent Systemsat the University of California, Irvine. Objek penelitian adalah data pasien sebanyak 100 data pasien Diabetes Mellitus dan 100 data pasien nonDiabetes Mellitus , yang terdiri dari 5 variabel input dan 1 variabel output. Penelitian ini bertujuan untuk membuat aplikasi diagnosa penyakit Diabetes Mellitus menggunakan Fuzzy Inference System Metode Mamdani.

\section{B. Riset Pendahuluan}

Pada penelitian riset pendahuluan dilakukan pembagian data, yaitu $60 \%$ sebagai data training, 40\% sebagai data testing. Setelah itu dilakukan langkah-langkah pengembangan Fuzzy Inference System Metode Mamdani.

C. Hasil Penelitian

Data hasil tes laboratorium pasien Diabetes Mellitus sebanyak 200 kasus yang akan dianalisis dijadikan variabel fuzzy dalam diagnosa penyakit Diabetes Mellitus dengan bantuan software matlab.

Ada 5 kriteria yang akan dianalisis dan dijadikan variabel fuzzy dalam diagnosa penyakit Diabetes Mellitus, yaitu :

1. Variabel Glukosa Plasma 2 jam

Variabel Glukosa Plasma 2 jam dibagi menjadi 3 himpunan fuzzy yaitu: NORMAL, SEDANG, dan TIDAK NORMAL. Himpunan fuzzy NORMAL akan memiliki domain $[0,4]$ dimana derajat keanggotaan NORMAL tertinggi (=1) terletak pada angka 0 - 3. Himpunan fuzzy SEDANG memiliki domain $[3,7]$ dimana derajat keanggotaan SEDANG tertinggi $(=1)$ terletak pada nilai 5 . Himpunan fuzzy TIDAK NORMAL akan memiliki domain $[6,10]$ dimana derajat keanggotaan

TIDAK NORMAL tertinggi $(=1)$ terletak pada angka $\geq 7$. Variabel Glukosa direpresentasikan dengan fungsi keanggotaan segitiga.

2. Variabel Tekanan Darah Diastolik

Variabel TekananDarah Diastolik dibagi menjadi 3 himpunan fuzzy yaitu: NORMAL, SEDANG, dan TIDAK NORMAL. Himpunan fuzzy NORMAL akan memiliki domain $[0,4]$ dimana derajat keanggotaan NORMAL tertinggi $(=1)$ terletak pada angka 0 - 3. Himpunan fuzzy SEDANG memiliki domain $[3,7]$ dimana derajat keanggotaan SEDANG 
tertinggi $(=1)$ terletak pada nilai 5. Himpunan fuzzy TIDAK NORMAL akan memiliki domain $[6,10]$ dimana derajat keanggotaan TIDAK NORMAL tertinggi $(=1)$ terletak pada angka $\geq 7$. Variabel Tekanan Darah Diastolik direpresentasikan dengan fungsi keanggotaan segitiga.

Tabel 2. Variabel dan nilai kategori

\begin{tabular}{|c|c|c|c|c|}
\hline $\begin{array}{l}1 \\
1\end{array}$ & Variabel & Nilai & Klasifi-kasi & $\begin{array}{l}\text { Dom } \\
\text { ain }\end{array}$ \\
\hline \multirow{3}{*}{ : } & \multirow{3}{*}{ Glukosa plasma 2 jam } & $187-232$ & $\begin{array}{c}\text { Tidak } \\
\text { Normal }\end{array}$ & $\begin{array}{c}{[6} \\
10]\end{array}$ \\
\hline & & $141-186$ & Sedang & $\begin{array}{l}{[3} \\
7]\end{array}$ \\
\hline & & $44-140$ & Normal & $\begin{array}{l}{[0} \\
4]\end{array}$ \\
\hline \multirow{3}{*}{ : } & \multirow{3}{*}{$\begin{array}{l}\text { Tekanandarah } \\
\text { diastolik(mm Hg) }\end{array}$} & $92-122$ & $\begin{array}{c}\text { Tidak } \\
\text { Normal }\end{array}$ & $\begin{array}{c}{[6} \\
10]\end{array}$ \\
\hline & & $81-91$ & Sedang & $\begin{array}{l}{[3} \\
7]\end{array}$ \\
\hline & & $30-80$ & Normal & $\begin{array}{l}{[0} \\
4]\end{array}$ \\
\hline \multirow{3}{*}{ : } & \multirow{3}{*}{ Indeks massa tubuh } & $34-67$ & $\begin{array}{c}\text { Tidak } \\
\text { Normal }\end{array}$ & $\begin{array}{l}6 \\
10]\end{array}$ \\
\hline & & $26-33$ & Sedang & $\begin{array}{l}3 \\
7]\end{array}$ \\
\hline & & $18-25$ & Normal & $\begin{array}{l}{[0} \\
4]\end{array}$ \\
\hline \multirow{3}{*}{4} & \multirow[t]{3}{*}{ Fungsisilsilah Diabetes } & $0.54-2.29$ & $\begin{array}{c}\text { Tidak } \\
\text { Normal }\end{array}$ & $\begin{array}{c}6 \\
10]\end{array}$ \\
\hline & & $0.50-0.53$ & Sedang & $\begin{array}{l}{[3} \\
7]\end{array}$ \\
\hline & & $0.08-0.49$ & Normal & $\begin{array}{l}{[0} \\
4]\end{array}$ \\
\hline \multirow{3}{*}{$!$} & \multirow{3}{*}{ Jumlah kali hamil } & $10-17$ & $\begin{array}{c}\text { Tidak } \\
\text { Normal }\end{array}$ & $\begin{array}{c}6 \\
10] \\
\end{array}$ \\
\hline & & $5-9$ & Sedang & $\begin{array}{l}{[3} \\
7]\end{array}$ \\
\hline & & $0-4$ & Normal & $\begin{array}{l}{[0} \\
4]\end{array}$ \\
\hline
\end{tabular}

3. Variabel Indeks Masa Tubuh

Variabel Indeks Masa Tubuh dibagi menjadi 3 himpunan fuzzy yaitu: NORMAL, SEDANG, dan TIDAK NORMAL. Himpunan fuzzy NORMAL akan memiliki domain [0,4] dimana derajat keanggotaan NORMAL tertinggi $(=1)$ terletak pada angka 0 - 3. Himpunan fuzzy SEDANG memiliki domain $[3,7]$ dimana derajat keanggotaan SEDANG tertinggi $(=1)$ terletak pada nilai 5 . Himpunan fuzzy TIDAK NORMAL akan memiliki domain $[6,10]$ dimana derajat keanggotaan TIDAK NORMAL tertinggi $(=1)$ terletak pada angka $\geq 7$. Variabel Indeks Masa Tubuh direpresentasikan dengan fungsi keanggotaan segitiga.

4. Variabel Fungsi Silsilah Diabetes

Variabel FungsiSilsilah Diabetes dibagi menjadi 3 himpunan fuzzy yaitu: NORMAL, SEDANG, dan TIDAK NORMAL. Himpunan fuzzy NORMAL akan memiliki domain [0,4] dimana derajat keanggotaan NORMAL tertinggi (=1) terletak pada angka 0 - 3. Himpunan fuzzy SEDANG memiliki domain $[3,7]$ dimana derajat keanggotaan SEDANG tertinggi (=1) terletak pada nilai 5. Himpunan fuzzy TIDAK NORMAL akan memiliki domain [6,10] dimana derajat keanggotaan TIDAK NORMAL tertinggi $(=1)$ terletak pada angka $\geq 7$. Variabel Fungsi Silsilah Diabetes direpresentasikan dengan fungsi keanggotaan segitiga.

5. Variabel Jumlah Kali Kehamilan

Variabel Jumlah Kali Kehamilan dibagi menjadi 3 himpunan fuzzy yaitu: NORMAL, SEDANG, dan TIDAK NORMAL. Himpunan fuzzy NORMAL akan memiliki domain $[0,4]$ dimana derajat keanggotaan NORMAL tertinggi $(=1)$ terletak pada angka 0 - 3. Himpunan fuzzy SEDANG memiliki domain $[3,7]$ dimana derajat keanggotaan SEDANG tertinggi $(=1)$ terletak pada nilai 5. Himpunan fuzzy TIDAK NORMAL akan memiliki domain $[6,10]$ dimana derajat keanggotaan TIDAK NORMAL tertinggi $(=1)$ terletak pada angka $\geq 7$. Variabel Jumlah Kali Hamil direpresentasikan dengan fungsi keanggotaan segitiga. 
D. Proses Mamdani

Fuzzifikasi

Fungsi derajat keanggotaan yang digunakan adalah fungsi segitiga.

Fungsi Segitiga:

$$
\mu[\mathrm{x}]=\left\{\begin{array}{rl}
0 & x \leq \text { aataux } \geq c \\
& \frac{x-a}{b-a} a \leq x \leq b \\
\frac{b-x}{c-b} b & \leq x \leq c
\end{array}\right.
$$

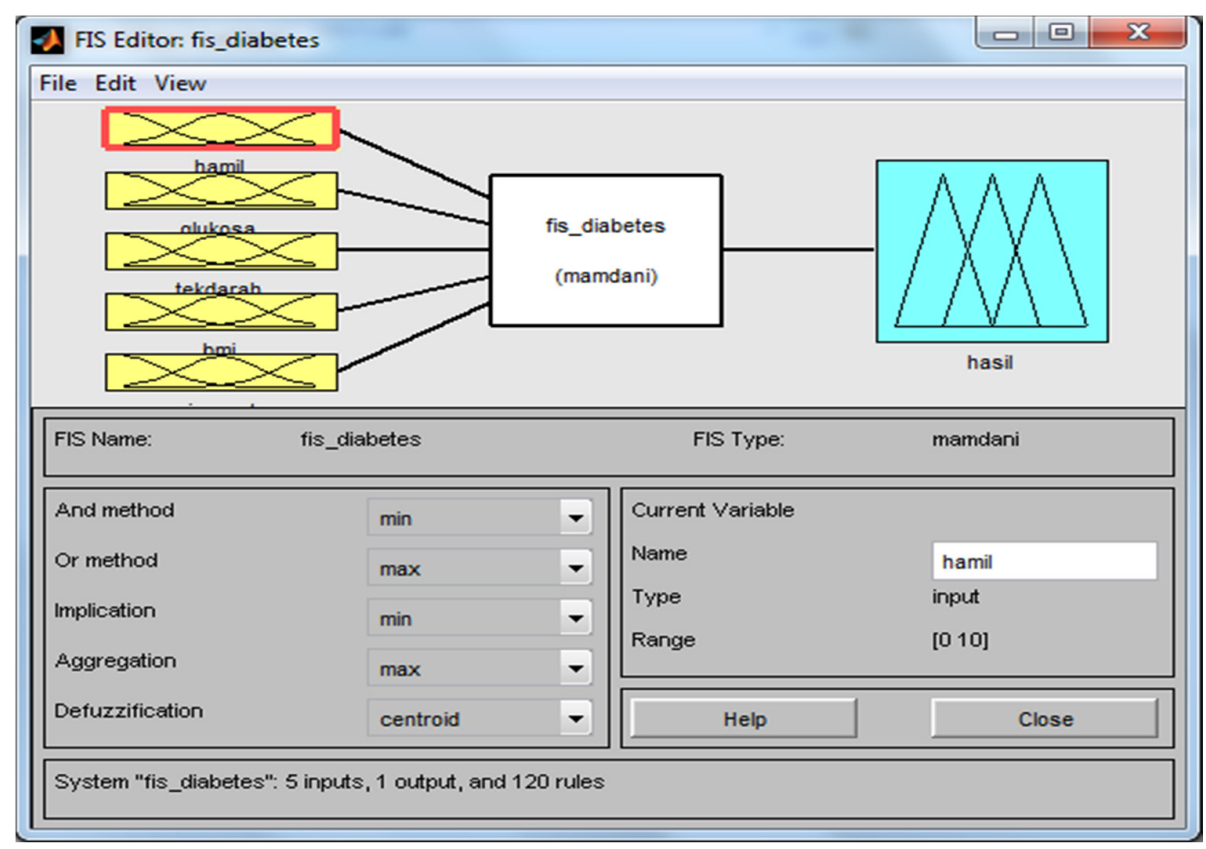

Gambar 3. FIS Editor Diabetes Mellitus

Variabel tersebut dibentuk dalam himpunan fuzzy dengan bantuan tool Matlab dengan pendekatan fuzzy tipe mamdani.

E. Pembuatan Aturan Fuzzy

Basis pengetahuan dalam perancangan aplikasi ini sangatlah diperlukan, yang berisi aturan-aturan atau rule yang berguna dalam penentuan keputusan sebagai hasil output sistem. Perancangan aturan-aturan ini merupakan langkah setelah pembentukan himpunan fuzzy. 


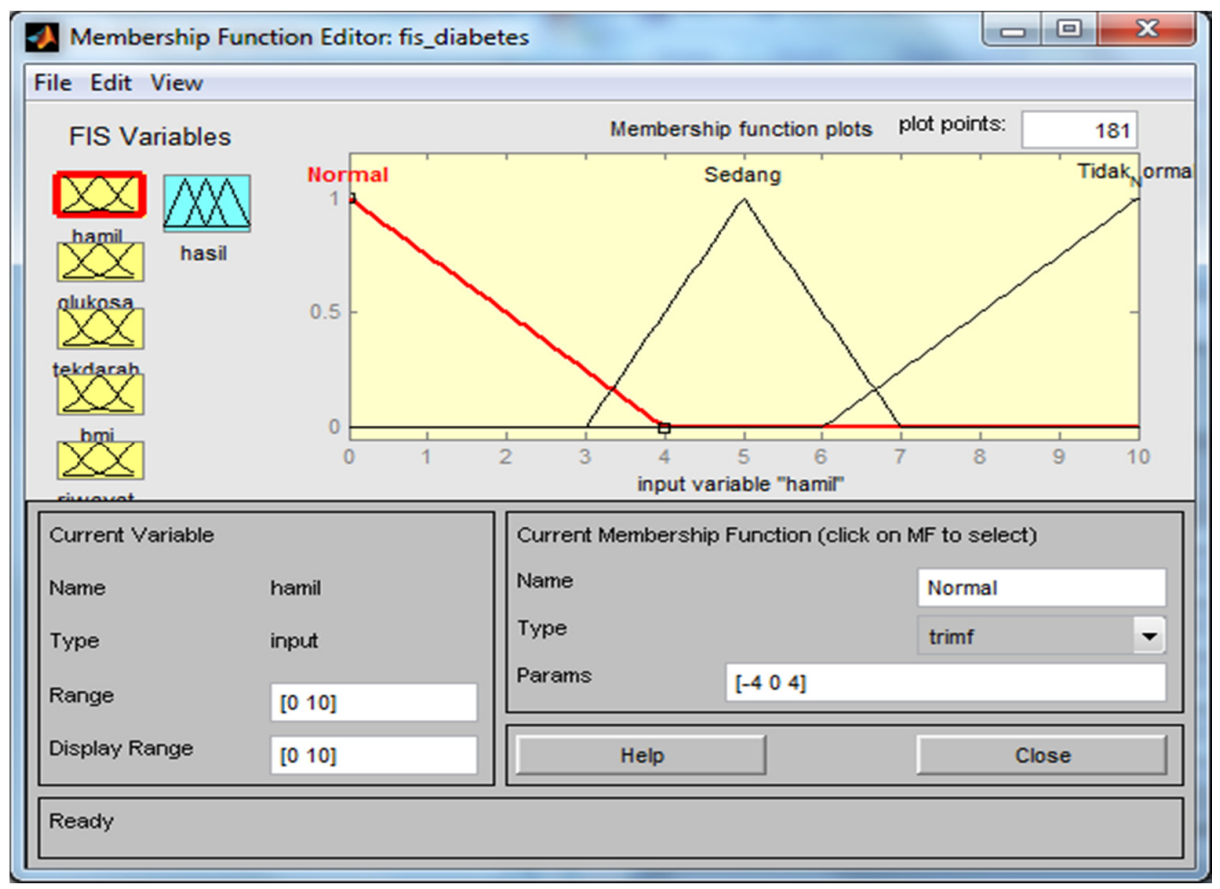

Gambar 4. Membership Function Editor Variabel Jumlah Kali Hamil

Dari aturan yang telah disusun berdasarkan keputusan dokter sebagai pakar nantinya dapat digunakan sebagai penentuan keputusan dalam diagnosa penyakit diabetes mellitus.

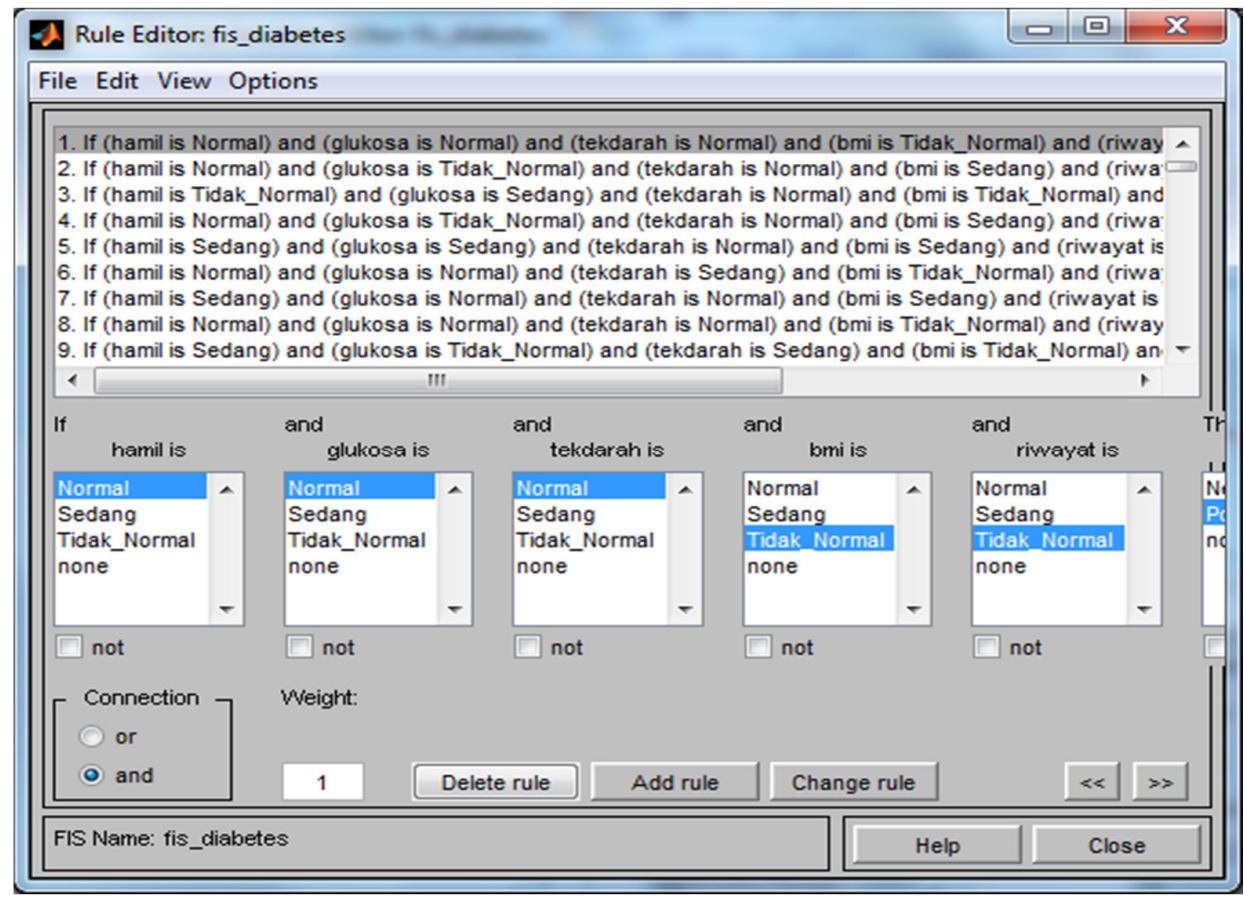

Gambar 5. Rule Editor Diabetes Mellitus 
Setelah proses penginputan data selesai, maka selanjutnya akan dilakukan proses diagnosa penyakit diabetes mellitus yang akan menghasilkan output berupa positif diabetes mellitus atau negatif diabetes mellitus . Berikut adalah GUI (Graphical User Interface) untuk diagnosa penyakit diabetes mellitus.

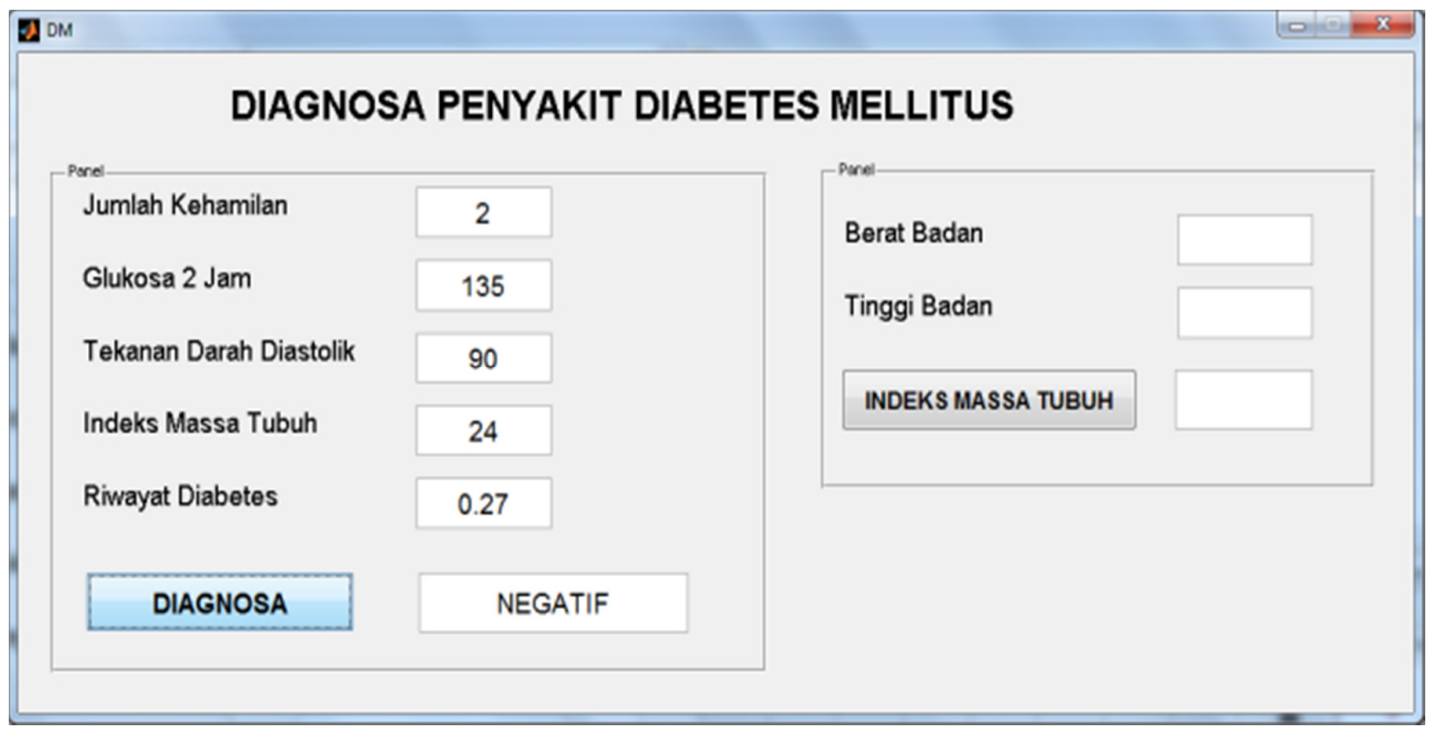

Gambar 6. GUI Diagnosa Penyakit Diabetes Mellitus

Pada analisis hasil dilakukan uji coba terhadap data hasil tes laboratorium pasien diabetes mellitus dan non diabetes mellitus. Data tersebut merupakan data yang pernah di diagnosa oleh pakar dan dijadikan Public Dataset yaitu data set dapat diambil dari repositori publik yang disepakati oleh para peneliti data mining : UCl Repository [8]. Uji coba dilakukan untuk mengetahui ketelitian output aplikasi dan untuk mengetahui sejauh mana kemampuan aplikasi dalam mendeteksi penyakit diabetes mellitus.

Dari delapan puluh data testing yang di uji coba dengan parameter hasil tes laboratorium yang berbeda, didapatkan bahwa :

1. Nilai dari tiap parameter sangat berpengaruh terhadap hasil yang diperoleh.

2. Rule yang telah dibuat berpengaruh pada proses evaluasi rule yang terjadi, maka semakin tepat rule yang dibuat maka hasil yang diperoleh akan lebih akurat.

3. Rule yang dibuat hanya untuk menentukan diagnosa penyakit diabetes mellitus dengan melihat hasil tes laboratorium, karena untuk mendapatkan hasil yang optimal membutuhkan penalaran yang lebih lengkap dari para pakar.

4. Kemampuan aplikasi dalam mendiagnosa penyakit diabetes mellitusdigunakan untuk mendapatkan informasi kesehatan diabetes mellitussehingga pasien bisa segera mengambil langkah preventif dalam mencegah atau melakukan pengobatan secara dini.

5. Hasil ujicoba oleh bidan dan perawat puskesmas adalah $100 \%$ aplikasi ini sesuai dengan diagnosa dokter.

\section{KESIMPULAN}

Berdasarkan pembahasan hasil penelitian, maka dapat diambil kesimpulan : diagnosa penyakit diabetes mellitus dapat dibangun dengan pendekatan logika fuzzy, penentuan diagnosa penyakit dengan sistem pendukung keputusan menggunakan pendekatan logika fuzzy lebih objektif dari pada diagnosa penyakit secara manual, penentuan diagnosa penyakit dengan sistem pendukung keputusan menggunakan pendekatan logika fuzzy lebih efektif dan efisien, penentuan diagnosa penyakit dengan pendekatan logika fuzzy menggunakan 5 kriteria dalam menentukan keputusan. Fungsi dari aplikasi ini untuk mempermudah masyarakat dan pekerja klinik dalam diagnosa penyakit diabetes mellitus secara cepat dan efisien.Hasil ujicoba oleh bidan dan perawat puskesmas adalah 100\% aplikasi ini sesuai dengan diagnosa dokter. 


\section{REFERENSI}

[1] Marimin. 2012. Penalaran Fuzzy, Materi Kuliah, Departemen Ilmu Komputer, Institut Pertanian Bogor.

[2] Chandrawinata, Dr. J , M.S., 2010. 10 penyakit moderen yang mematikan. [Online] Available at: <http://poskota.co.id/beritaterkini/2010/04/01/1 0-penyakit-modern-yangmematikan> [Accessed 13 juni 2012].

[3] Kusumadewi, S \& Purnomo, H. 2010. “Aplikasi Logika Fuzzy Untuk Pendukung Keputusan”, Edisi ke-2 Graha IImu Yogyakarta.

[4] Marimin dan Maghfiroh, N. 2010. “Aplikasi Pengambilan Keputusan dalam Manajemen Rantai Pasok", Cetakan 1, IPBPress, Bogor.

[5] Kusumadewi, S. 2002. Analisis Desain Sistem Fuzzy menggunakan Tool Box Matlab, Edisi ke-1 Graha Ilmu Yogyakarta.

[6] Haryanto, T. 2012. Logika Fuzzy dan Sistem Pakar Berbasis Fuzzy, Materi Kuliah, Departemen Ilmu Komputer, Institut Pertanian Bogor.

[7] Wahono, RS. 2012. Proses Data Mining. Materi kuliah IImu Komputer. Brainmatics Cipta Informatika. http://diabetesmelitus.org/penyakit-diabetes-melitus/ 